\title{
A Gestalt Theoretic Perspective on the User Experience of Location-Based Services
}

\author{
Jeni Paay and Jesper Kjeldskov \\ Aalborg University, Department of Computer Science \\ Fredrik Bajers Vej 7E, DK-9220 Aalborg East, Denmark \\ \{jeni, jesper\}@cs.aau.dk
}

\begin{abstract}
Location-based services provide mobile users with information and functionality tailored to their geographical location. Within recent years these kinds of context-aware mobile systems have received increasing attention from software industry as well as from researchers within a wide range of computing disciplines. However, while a lot of research has been done into sensing, adapting and philosophizing over the complex concept of "context", little theoretically based knowledge exists about why, from a user experience perspective, some context-aware system designs work well and why others don't. Contributing to this discussion, this paper suggests the perspective of "Gestalt theory" as a potential theoretical framework for understanding the use of this class of computer systems, and argues that describing the user experience of location-based services through Gestalt theory's principles of proximity, closure, symmetry, continuity, and similarity can help explain how people make sense of small and fragmented pieces of information on mobile devices in context.
\end{abstract}

\section{Categories and Subject Descriptors}

H5.2. [Information interfaces and presentation (e.g., HCI)]: User Interfaces - User-centered design, Graphical user interfaces.

\section{General Terms}

Design, Human Factors.

\section{Keywords}

Location-Based Services, Gestalt Theory, Field Study

\section{INTRODUCTION}

Location-based services represent an emerging class of computer systems providing mobile device users with information and functionality related to their geographical location. Within recent years, this subset of context-aware mobile computer systems have received increasing attention from researchers within a range of computer science disciplines as well as from software industry. Location-based services open a new market for network operators and service providers to develop and set up value-adding new services for users on the move, such as helping find nearby shops or friends, advertising traffic conditions, supplying routing

OzCHI 2007, 28-30 November 2007, Adelaide, Australia. Copyright the author(s) and CHISIG. Additional copies are available at the ACM Digital Library (http://portal.acm.org/dl.cfm) or can be ordered from CHISIG(secretary@chisig.org)

OzCHI 2007 Proceedings, ISBN 978-1-59593-872-5 information, and augmenting the built environment of cities with a ubiquitous layer of information about, for example, people, places, and activities. Recent advances in technology have fuelled the development and uptake of a wide range of location-based services. PDAs and 3G mobile phones with GPS and other positioning capabilities have become increasingly affordable and popular, and more and more service providers have begun to develop and offer innovative information services that integrate wide-area broadband Internet access, web resources and geographical information. Also, generally available geographical information systems (GIS) such as Google Earth and Google Maps have rapidly become popular media for people to access location-related information and even publish it themselves (i.e., relating picture blogs content to geographical places and publishing GPS coordinate trails for others to follow).

The development of location-based services for mobile devices faces many challenges ranging from issues of determining people's location and orientation in physical space, how to combine satellite imaging, 3D models and cartography, through to issues of what information to provide in response to a particular location, and how to facilitate suitable user interaction with this content. Within the Mobile HCI community it has been widely argued that researchers, designers and software developers need to look more broadly at the context of use of mobile devices and systems in order to understand mobile use better and to be able to produce good and relevant solutions [19]. In response to this, huge efforts have been put into both ethnographic-style studies of mobile work activities, and field studies of technology in use. However, while a lot of research has been done into sensing, modeling and adapting to context, as well as philosophizing over the complex concept of "context" (e.g. [9]), very little work has provided theoretically informed foundations informing the design of context-aware systems, or explained, from a user experience perspective, why some solutions work well and why others don't. Hence, generally applicable rules and guidelines for interaction design, as we know them for desktop and web applications, are lacking, and more research is needed into the user experience of this emerging class of applications. Contributing to this research, this paper presents a user experience study of a prototype location-based service and looks at how people perceive the ensemble of mobile devices and use context from the perspective of Gestalt theory and its principles of proximity, closure, symmetry, continuity, and similarity as a potential theoretical framework for understanding the user experience of this class of mobile systems. In suggesting this perspective on human perception and thinking in relation to technology use, we align ourselves closely with the work of Frøkjær and Hornbæk [15], [16] on metaphors of human thinking for describing aspects of human-computer interaction. 
We have been studying the user experience of location-based services through a 2-year project investigating the deployment of mobile and pervasive computing technologies in urban environments. The $e$-Spective project took its origin in the newly opened civic structure of Federation Square in Melbourne, Australia and involved a series of field studies of urban socialising behaviour within the built environment of inner cities as well as the development and evaluation of a prototype locationbased service providing an informational overlay to Federation Square [22], [28]. In addition to learning about interaction design for location-based services on mobile devices, one of our most interesting (and somewhat surprising) findings from studying people's use of the prototype location-based service was that people were extremely good at making sense from small and fragmented pieces of information. When faced with incomplete or ambiguous information, people wanted to put the pieces together. They wanted to connect the dots, and they were very good at it. This finding prompted two questions: 1) How can we explain this phenomenon?; and 2) How can knowledge about this phenomenon inform the design of similar location-based services? Motivated by these questions we have analysed our video and interview data from field evaluations of the prototype system from multiple theoretical angles. In doing this, we have found that the perspective of Gestalt theory provides a very useful, and yet simple lens for describing and explaining how people make sense of the content of mobile information systems situated in context. In this paper, we focus on the first question of explaining the observed phenomenon.

The paper is structured as follows. First we introduce related work within mobile Internet technologies and location-based services. We then turn our attention towards Gestalt theory and how this theoretical approach to human perception and thinking has previously been applied within HCI and used to explain and inform qualities of graphical screen design. Following this, we introduce the Federation Square case study, the prototype system developed, and the field study of prototype use. Illustrated with examples from our findings, we then reflect on the ensemble of mobile device and use context in the user experience of our location-based services from a Gestalt theory perspective. Finally, we sum up and suggest avenues for further research.

\section{THE MOBILE INTERNET AND LOCATION-BASED SERVICES}

Within the last decade there has been a huge focus on the development of mobile information and communication technologies bringing the potentials of the Internet to the mobile user within a wide range of use domains for work as well as for leisure. Following the widespread uptake and commercial success of the Short Message Service (SMS) on mobile phones since the late 1990's, significant attention and resources have been devoted to the development of the next generations of mobile network services, protocols and infrastructure, known as $2 \frac{1}{2} \mathrm{G}$ and $3 \mathrm{G}$ mobile telephony [31]. MMS (Multimedia Message Service) was developed as an extension of SMS, allowing users to exchange rich media content rather than just text and simple graphics, and WAP (Wireless Application Protocol) was developed to allow mobile access to a downscaled version of the web. On the network level, GPRS (General Packet Radio Service) allows faster, affordable and always-on data connections to the Internet from mobile devices. With the introduction of the UMTS (Universal Mobile Telephone System) (3G) network, the speed of mobile data connections now matches their hard-wired counterparts, thus allowing realistic mobile use of, for example, the world wide web. However, while commercially available technologies have made the Internet mobile, fast, accessible and relatively cheap, uptake by the general population has not met the IT industry's expectations (e.g. [7], [1]). Supporting this trend for Australia, Ericsson recently released a survey of the consumer patterns of 2000 people, which shows that while Australians are increasingly interested in the mobile Internet, few are actually using it [11].

From an HCI perspective there are several reasons for this. Firstly, while unquestionably containing information and functionality relevant to mobile users, most Internet services are not well designed for mobile use (e.g. [12]). They are designed for desktop use, and require a lot of user input and visual and cognitive attention. In contrast, the mobile Internet is typically accessed through devices with small screens and limited means of input used in very dynamic settings. Thirdly, services for the mobile Internet are currently designed to facilitate doing, while mobile, the things we do at our desktop. They do not relate to mobile use context but look the same at home, on the bus, in a café, or walking down the street - situations with very different requirements (e.g. [24]). If we want to bridge the gap between interest and actual use of the mobile Internet, we must do better. We must support a user experience that takes into account the wholeness of technology and context, and we must enable people to do relevant things that they couldn't do before.

Advances in technology have made it possible for mobile computers to sense or access information about users' context such as location, social setting, activity, computational resources, etc. (e.g. [17]). Recent research has demonstrated that using such information to make mobile computer systems "context-aware" can increase usability within highly specialised domains such as healthcare and industrial process control. One of the most promising aspects of user context for a mobile computer system to respond to is location [20], [13], [21]. The potential benefits of location-based services for the mobile Internet are several. By making a mobile Internet service aware of the user's location, developers can streamline it to present information and functionality that is particularly relevant at a specific place or within a specific distance. As a fictive example, a location-based mobile Internet service for a train station could respond to the user's location, time, activity etc., by presenting only information about departures from this or nearby stations, within a short period of time, to destinations matching upcoming appointments.

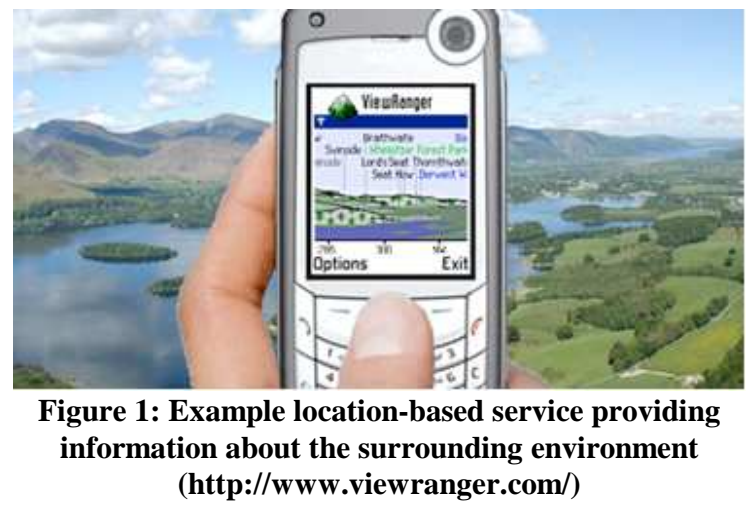


Examples of commercially available location-based services are still very few and mostly restricted to SMS-based services broadcasted to subscribing mobile phone users in particular areas. However, new technology is fuelling the development of more advanced services. PDAs and 3G mobile phones with GPS and other positioning capabilities have become affordable and increasingly popular, and some providers have begun to offer services that integrate wide-area broadband wireless Internet access, web resources and geographical information. As an example, ViewRanger (Figure 1) provides 3D models of the user's surroundings with superimposed information links on GPS enabled $3 \mathrm{G}$ phones in parts of the UK. Other services, such as TrackStick and Phone2Gearth, allow people to track their geographical movements, annotate it with media content such as text, images and video, and then publish it through GIS systems such as Google Earth (Figure 2). In a similar fashion, Sony has recently announced that their next generation of cameras and camcorders will be able to record GPS position data and allow people to publish their media on an online map.

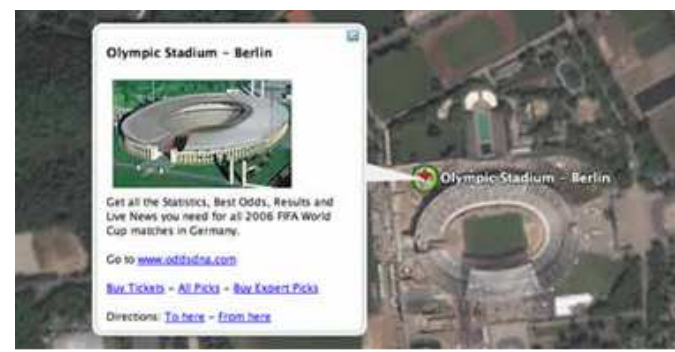

Figure 2: location-based information posted in Google Earth

Yet developing successful location-based services for the mobile Internet is not trivial. It inherits challenges of context-awareness described in the literature, such as issues of user control, privacy, and determining people's location in physical space, as well as introducing new ones. Given the novelty of location-based services, little is known about peoples' use of such of services. It is unclear how users perceive and use information provided through location-based services, what content is considered relevant (and what is not) and how people will adopt and appropriate information services that react to their location and combine, for example, web content, satellite imaging, 3D graphics, and cartography.

In the following section, we turn our attention towards Gestalt theory, which we have found to be a useful perspective for explaining the interplay between context and technology in the user experience of location-based services.

\section{GESTALT THEORY}

Gestalt theory evolved from explorations of human perception in the discipline of Psychology in the early twentieth century aiming to explain how people organize different information from their environment. The founders of Gestalt psychology are acknowledged as Max Wertheimer, Wolfgang Kohler and Kurt Koffka. Wertheimer applied Gestalt psychology to problem solving, Koffka to applied psychology and child psychology, and Kohler to learning strategies. Gestalt theory has over a hundred different laws that pertain to human perception, including visual and auditory. These laws of Gestalt psychology are fundamental in understanding the way people see and understand their surroundings [4].

Gestalt theory explains how we perceive objects in our environment. The Gestalt viewpoint says that "things are affected by where they are and by what surrounds them" [2, p. 49], acknowledging the importance of context in how we perceived things. From the Gestalt perspective, new information is seen as organized and bridged to prior knowledge to form an organized whole, and it is the combination of the context that something sits in as well as our prior knowledge that allows us to interpret what we are looking at or listening to [29]. Hence, Gestaltists believe that we intuitively perceive things as a coherent unit or object and that this is an innate human ability [23]. When we are presented with something in our physical environment that is ambiguous, we use our prior knowledge of the world to make sense of it by filling in the blanks in the current information [32].

\subsection{Gestalt Theory in HCI}

Gestalt theory is included in several prominent human-computer interaction primers (e.g. [3], [23], [8], [29]), and is introduced for its general application to the design of information screens and as providing interface designers with a theoretically informed understanding of how information screens will likely be perceived by users. Gestalt theory, as it has been explored within humancomputer interaction, consists only of a small subset of the original Gestalt laws in the form of a set of principles of perceptual organization that can be applied to interface design to improve communication between user and system. For the purpose of this study, we have identified five such key principles, which are generally acknowledged within HCI. These are illustrated in figure 3 .

The principles of perceptual organization and other concepts derived from Gestalt laws have influenced many research areas related to HCI such as map reading, graph drawing, image retrieval, computer vision, pattern recognition, design of auditory displays and musical studies etc. Of particular interest to this paper is the research that has applied Gestalt principles to HCI analysis, design and evaluation.

Due to the historical starting point of applying Gestalt theory to people's learning strategies, most of the early HCI research involving Gestalt theory focus on instructional design, with the purpose of structuring learning materials, including print-based,

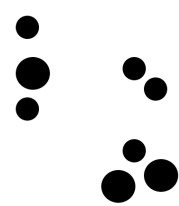

Proximity - things that are located near each other, in space or time, are perceived as belonging together

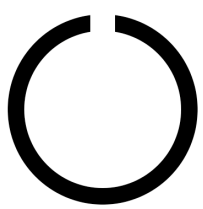

Closure - things are perceived as complete or whole, even when part of the information is missing

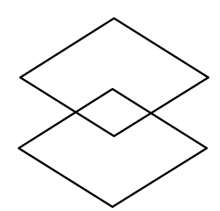

Symmetry - when things have symmetrical parts or borders, they are perceived as a coherent whole

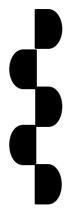

Continuity - we perceive things as continuous patterns rather than disjointed ones

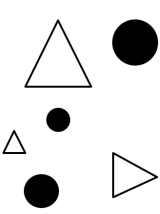

Similarity - things that look or sound alike are perceived as belonging together

Figure 3: Five key principles of perceptual organization for interaction design derived from Gestalt theory 
multimedia teaching presentations, through to more recent investigations into the design of computer based education (CBE) systems. The work of early instructional design researchers involving the use of Gestalt theory aimed at enhancing knowledge gained from written instructions through increasing perceptual accessibility [10], [25]. Later research by Smith-Gratto and Fisher [32] looked at instructional screen design using Gestalt theory to develop a way of planning and presenting informational elements to help students to learn more effectively. Using the arrangement of information both on a screen and between screens, they produced practical guidelines on how to design instructional screens based on the principles of perceptual organization. More recently, Chang et al. [5] have distilled their own set of relevant Gestalt laws for educational computer screen design from the original writings of the Gestalt psychologists to test the usefulness of the laws in visual screen design.

As the graphical user interface became the predominant interface of computer systems during the 1990's, it was important for HCI researchers to provide interface designers with an understanding of the human perception of operating these new information-rich types of interfaces and with guidance on how to design them better. In response, researchers applied Gestalt principles of perceptual organization to general screen design in order to create sets of design principles and guidelines for optimizing their graphical layouts. Important concepts of interface design, which are now considered elementary, such as consistency, visual hierarchy, grouping, legibility and contrast can be seen as derived from Gestalt theory [30]. This application of the Gestalt laws to interface design is also demonstrated by, for example, Mullet and Sano [26], Roth [30], Borchers et al. [4] and Lauesen [23]. In more recent work within HCI, Gestalt theory's principles of perceptual organization have been used as a basis for developing design guidelines for new paradigms of interaction design with multi-sensory displays that combine visual, auditory and haptic elements [6]. Gestalt theory principles has also recently been interlinked with a pattern methodology for creation of a theoretical framework facilitating the incorporation of knowledge about human perception into the early stages of user interface design [14]. Beyond the creation of principles and guidelines for screen design, recent research has also explicitly used Gestalt theory in the evaluation of existing interface designs. In acknowledging the importance of human perception in measuring the quality of web page design, Hsiao and Chou [18] used a combination of Gestalt grouping principles and fuzzy set theory from mathematics to develop a method to measure the Gestalt-like perceptual degrees of a web page design to evaluate the "wholeness" of that page.

While much of the Gestalt related research within HCI is about graphical interface design, Oviatt et al. [27] take a broader application of Gestalt principles by using Gestalt theory to analyse not just the computer screen but also the interaction situation. Aimed at the design of adaptive multimodal interfaces and providing a framework for understanding user interaction with multimodal information systems, they studied technology use in context, and observed, among others, how speakers tailor their language to accommodate the listener's perceptual capabilities. Explaining this and other phenomena, they applied Gestalt principles as a theoretical lens to look at both the user's perception of the interface and at their production of communication patterns during its use.
In the study reported in this paper, we have taken an approach that is similar to that of Oviatt et al. [27]. Rather than applying Gestalt principles to the design of the interface only, we view the computer screen as merely a small area within the larger context of the physical environment in which it is situated. In line with Gestalt theory's concept of "wholeness", the environment and the computer screen are seen as creating a unique perceptual whole, rather than as the simple sum of the individual parts. From this perspective, our study looks at the cognitively perceived ensemble of technology and surroundings as experienced when people are using location-based services in context.

\section{CASE STUDY: THE "JUST-FOR-US" LOCATION-BASED SERVICE}

Inquiring into the user experience of location-based services we have designed, implemented and evaluated a prototype locationbased service, Just-for-Us, providing an informational overlay to the civic space of Federation Square in Melbourne, Australia (Figure 4). Federation Square is a relatively new civic structure covering an entire city block, providing a variety of activities to visitors including restaurants, cafés, bars, a museum, galleries, cinemas, retail shops and several public forums.

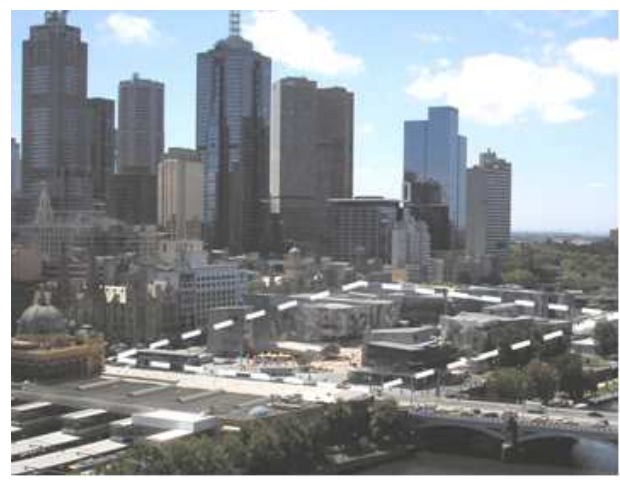

Figure 4: Federation Square, Melbourne, Australia, with surrounding skyline, train station and the river
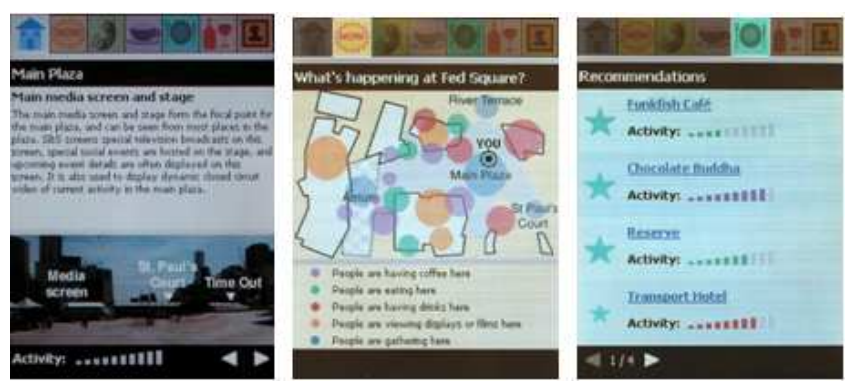

Figure 5: Screens from the Just-for-Us location-based service

The Just-for-Us system (Figure 5) keeps track of the location of the user and friends within close proximity. It also keeps a history of visits to places around the city (for details see [22]). On the basis of this, the service allows the user to explore his or her immediate surroundings through a series of annotated panoramic photographs. It also provides an overview of the level and nature of social activity taking place within proximity, and can make suggestions for places to go based on convenience, history, and social setting. 
The design of the prototype system was informed by a field study of situated social interactions at Federation Square exploring the interplay between people, technology and interactions in place. The user experience evaluation of the prototype was conducted as a combination of rapid ethnography and a think-aloud study. In analysing our field data from the perspective of Gestalt theory, we analysed the original video data, and used content analysis to derive initial codes and themes, we then affinity diagrammed these into higher-level concepts, guided by the principles of proximity, closure, symmetry, continuity, and similarity.

\section{DRAWING FROM A LARGER CANVAS}

In this section we discuss qualitative findings from our field study of location-based service use from the perspective of Gestalt theory's principles of perceptual organization as presented earlier as a lens for describing and explaining how people perceived the relationship between the mobile location-based service and their environment. Figures 6-10 are provided to illustrate the Gestalt principles in design and are not meant as specific design suggestions.

\subsection{Proximity}

Proximity played an important role in the way that people interpreted the information presented by the Just-for-Us prototype. This happened on two levels. Firstly, it happened within the screen, in line with general screen design principles. The onscreen annotations on the panoramic photographs were perceived as belonging to the object or location that they were directly placed on top of, and also grouped annotations were perceived as belonging together. In addition, circles on the map were perceived as applying to the places they were located near and groups of circles on the map were perceived as representing "busy" areas. Secondly, and particularly interestingly for the design of location-based services, information on the mobile device itself was seen as an annotation of the place people were situated in. People were grouping the system with objects in the environment, that is, the physical space acted as a "larger canvas" to draw from, on which the location-based service was just another piece of information to be perceived and integrated into the whole of the experience.

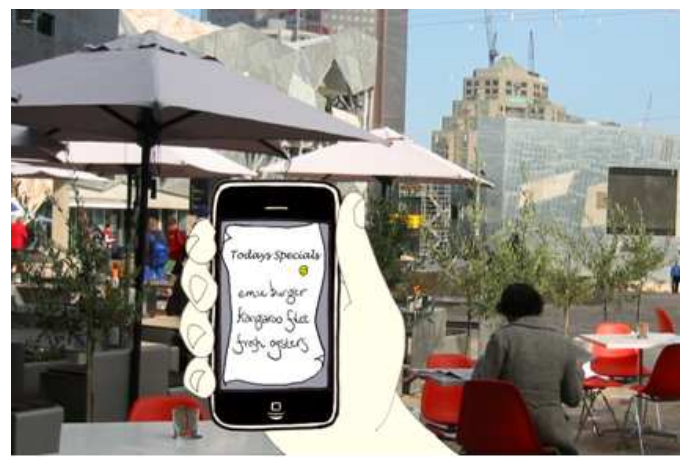

Figure 6: Perceiving information as an annotation of a place

In our evaluation we found that people easily understand when information presented by the system is specific to their current physical location, and they like it when they are automatically given information relevant to where they are. In fact, the close proximate relationship between the system and the world made people perceive the information content of the service as true although this wasn't actually always the case. For example, this happened when given the menu while they were at that particular café, or when presented with an annotated panoramic photograph of their location.

\subsection{Closure}

Closure is the Gestalt principle that best describes the phenomenon that people are capable of making sense from small bits of fragmented and ambiguous information. Pieces of information on the mobile device are combined with pieces of information from the physical environment to create a "whole", and missing parts of this combined picture are filled in on the basis of peoples' prior knowledge and sense-making abilities. As described by this Gestalt principle, people supply the missing information themselves, drawing from a larger canvas in "connecting the dots" to make it easier to understand their environment.

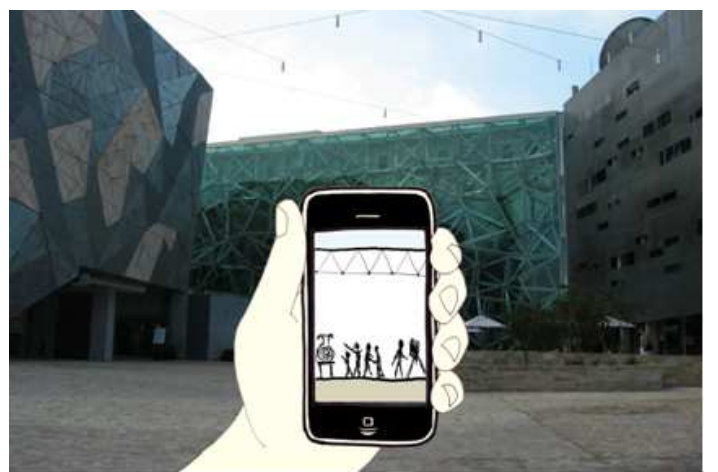

Figure 7: Filling in the blanks of ambiguous information

In our evaluation we found several examples of this. Although the maps used in the prototype were extremely simplistic line drawings with only a few annotations, people naturally perceived this as representing the much more complex real world around them. Annotations on the panoramic images supported people in "completing the picture" of what was behind the surrounding facades even though a large part of that picture was not visible to them. People also used their knowledge of familiar places referred to by the system as anchor points to resolve the layout of unfamiliar areas. As another example, closure played a major role in the manner in which people used the wayfinding information provided by the system. The principle of closure describes how people mentally complete incomplete graphical figures, such as a partial circle. In relation to wayfinding we found that this principle also applied to visualising a series of transition points as a complete path from A to B. As opposed to guidance systems that give highly detailed step-by-step instructions we found that people only needed fragmented detail to find their way around the space. Useful types of transition points were found to be references to familiar places, major entrances, landmarks (i.e., the river), or distinct architectural elements (i.e., the green glass wall). Another important finding in relation to closure was that in reducing the information presented to the user of a location-based service, the significance of remaining information increases. This means that even though people are highly capable of connecting the dots, they still need carefully chosen "dots" to do so.

\subsection{Symmetry}

Because people have a preference for symmetry, they made an effort to eliminate any asymmetry between the system and the real world. This was not used as much to piece together information to 
be able to understand it, as it was for the comfort of creating a coherent base on which to build understanding.

In our evaluation we observed that people strived for symmetry between the system and the world. Visually this was evident as they worked to align the panoramic images on the mobile device screen with the buildings around them even though this was not actually necessary to operate the system. Some people even expressed that they would like the panoramic images to automatically correspond to the direction they were physically facing. Offsets between the viewpoint of the panoramic images on the screen and the user's location affected the symmetry between the two. People found this disconcerting, even though it was only a few degrees difference in view and they could still easily make sense of the representation. The same phenomenon was observed when using maps in the system. In this situation many people changed the orientation of the mobile device so that it aligned with their surroundings in striving for symmetry between the system and the physical environment.

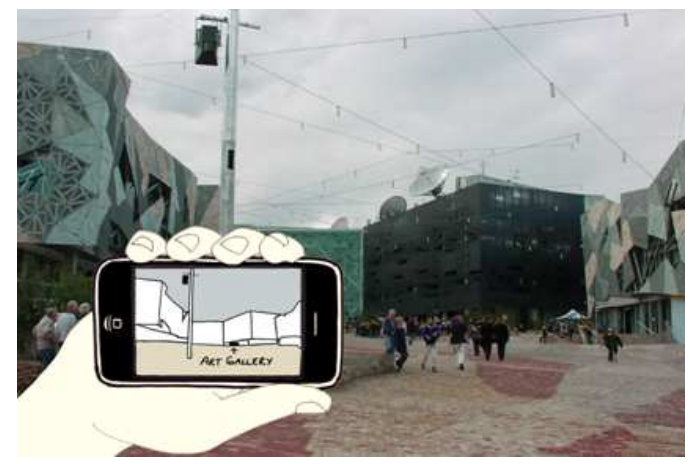

Figure 8: Making a symmetrical alignment

\subsection{Continuity}

In looking at the use of location-based services in context, the principle of continuity applies strongly to interaction over time. The fact that people have preferences for familiar places and paths indicates that interactions in a place do not happen as isolated events but are often an extrapolation of past experiences there. People have a trail of past interactions that they like to share with others, as much as they like to incorporate the trails of others into their own current experience. Rather than a random set of disjointed events, people tend to perceive their past experiences as interwoven in a continuous pattern. In this sense the larger canvas, which people draw from, consists not only of their mobile device and physical surroundings but also of their memories.

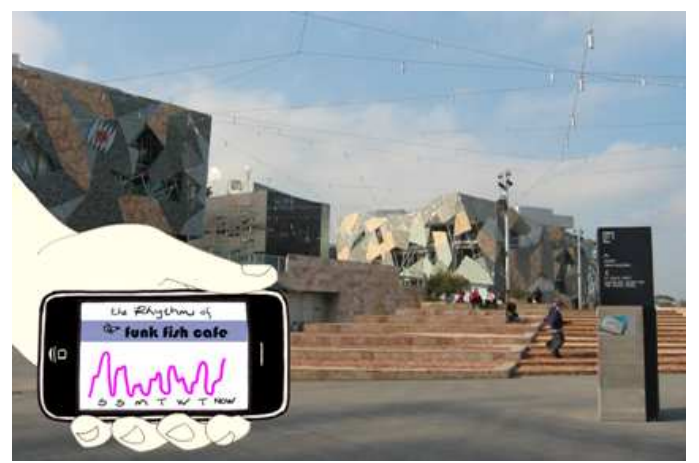

Figure 9: Experiencing a place continuously over time
In our evaluation we found that although interested in exploring new places, people were primarily interested in information about current events at their familiar places. In this way, they continue to weave a story of interactions over time. When exploring new places, people preferred places that had been recommended to them by friends, and other trusted sources (i.e., reputable food guides), drawing on the experiences of others rather than starting from nothing. In this way they are adding to the continuity of other peoples' stories as well as enriching their own. Continuity also played a role in relation to the interpretation of descriptors used in the system. Here there was a clear preference for persistent descriptors, for example, "the black building", which refers to a constant quality of that building, rather than "the sitting steps", which refers to a transient activity at those steps.

The importance of continuity also came to our attention in relation to a part of our prototype system where people misunderstood or were surprised that the location-based service adapted not only to location but also to their history of visits. Specifically, this happened when the system made suggestions for places to go based on where they had been in the past, but without indicating the rationale behind these recommendations. From the perspective of continuity, we had failed to represent to the user the trajectory of experiences from which these suggestions were drawn, thus making it impossible for people to see the recommendations as a part of their continuing experience with a place and an extrapolation of their past experiences.

\subsection{Similarity}

Finally, similarity played an enormous part in people's ability to make sense of the location-based service. Things in the physical environment were continuously aligned with images and other representations on the screen that matched or looked alike. Through this, information content in the system was perceived as belonging to the corresponding location or object in the world. This was not necessarily always a visual matching process. People were also able to draw on similarities between images and annotations on the screen and their knowledge about the physical environment, within and beyond visual range.

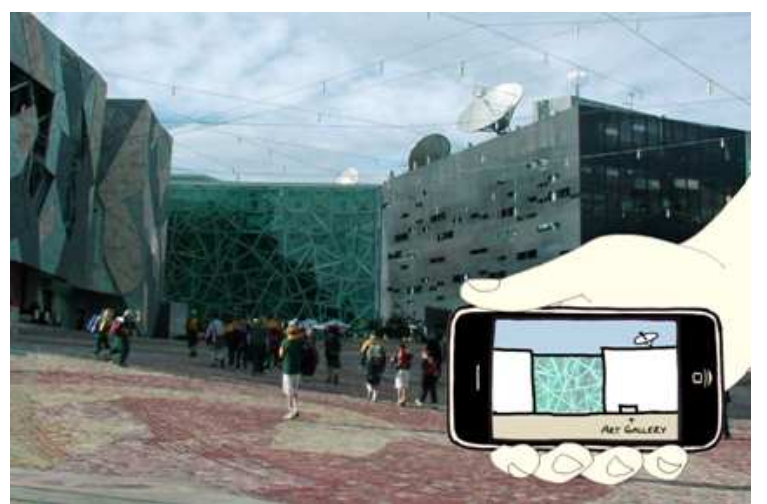

Figure 10: Matching similar things in system and real world

In our evaluation, similarity was primarily evident in matching physical objects and structures, such as media screens, a satellite dish, etc., to images on the screen. People looked for similarities in the outlines in their immediate, as well as distant, surroundings, such as the shape of buildings and the general skyline. They also used distinct features in their environment as anchor points for matching up the system and the world, for example, landmarks, unique patterns and colours on buildings. Finally, they used 
similarities between the visual style of the places surrounding them and the logos and other graphical elements in the system. Making sense on the basis of similarity happened not only on an iconic level, but also on a symbolic level. People often matched annotations on the screen, such as "the river", to the corresponding places in the world, and also matched up names in the system with signage in the physical environment. In fact, people found it perplexing if dominant signage in the world was not matched on the screen. Additionally, names in the system that hinted at the activity of a place, for example "Chinotto Café", were easily matched to a place if that activity was visually evident, in this case by the presence café tables and umbrellas. Again it was evident that in the use of the prototype location-based service people were drawing conclusions from the larger canvas - not just from the system or from the context.

\subsection{Implications for location-based services}

In Table 1 we summarise the observed implications for locationbased services, and give examples of key questions to be asked in the design and evaluation of a location-based service from a Gestalt theoretic perspective.

\section{CONCLUSIONS}

This paper has addressed the issue of explaining how people perceive and make sense of mobile location-based services situated in context. Prompted by the finding that people are extremely good at making sense from small and fragmented pieces of information when using location-based services, we have analysed empirical data from a user study of such a system in pursuit of explanations of this phenomenon. In response, we suggest the use of Gestalt theory as an analytical perspective for describing and explaining the interplay between people, mobile devices, and context of use through principles of perceptual organization. Exemplified by qualitative findings from our use

\begin{tabular}{|c|c|c|}
\hline Gestalt principle & Implications for location-based services & Example key questions \\
\hline Proximity & $\begin{array}{l}\text { People perceive information content as closely related } \\
\text { to their immediate location. }\end{array}$ & $\begin{array}{l}\text { Does the system act as an annotation of its physical location? } \\
\text { Can content in the user interface be grouped with objects in the } \\
\text { environment? }\end{array}$ \\
\hline Closure & $\begin{array}{l}\text { People are able to fill in the blanks of ambiguous and } \\
\text { fragmented information on the basis of their prior } \\
\text { knowledge and sense-making abilities. }\end{array}$ & $\begin{array}{l}\text { Can pieces of information in the user interface and in the surroundings be } \\
\text { combined to create a meaningful larger whole? } \\
\text { Does the system include clues about the relation between information in the } \\
\text { user interface and its context? } \\
\text { Does the system leave out redundant information already apparent through } \\
\text { the context? }\end{array}$ \\
\hline Symmetry & $\begin{array}{l}\text { People have a preference for symmetry between system } \\
\text { and surroundings in order to create a coherent base } \\
\text { from which to interpret the relation between the two. }\end{array}$ & $\begin{array}{l}\text { Does the system align information representations in the user interface with } \\
\text { the user's surroundings? } \\
\text { Does the system allow the user to align information representations in the } \\
\text { user interface with their surroundings? }\end{array}$ \\
\hline Similarity & $\begin{array}{l}\text { People group content and representations in the system } \\
\text { with elements in their physical surroundings based on } \\
\text { iconic and symbolic similarity. }\end{array}$ & $\begin{array}{l}\text { Does the user interface make use of representations that have similarities } \\
\text { with corresponding objects in the physical surroundings? } \\
\text { Does the user interface match elements in the surroundings, such as } \\
\text { prominent signage, landmarks, and visual style of a place or area? }\end{array}$ \\
\hline
\end{tabular}

Table 1: Five Gestalt principles, their implications for location-based services, and example questions for design and evaluation 289 evaluation, we have shown how Gestalt principles can be applied to the user experience of location-based services as a way of explaining peoples' use of contextually anchored mobile system design.

In their use of location-based services, people are not just drawing conclusions from their mobile device or their surroundings alone; they are drawing from a larger canvas to which both are contributing.

Proximity explains how information on the mobile device screen was seen as belonging to peoples' current physical location. Closure explains the phenomenon of people relating and making sense of fragmented information and adding the missing bits themselves. Symmetry describes the desire to align representations in the location-based service with the real world in order to obtain a coherent image from which to act. Continuity adds a temporal dimension and describes how information in a location-based service does not exist in isolation from peoples' history of interactions with it. Finally, similarity describes the mechanism of grouping specific elements in the system with corresponding elements in the surroundings. Acknowledging the importance of context, the Gestalt viewpoint is that things are affected by where they are and by what surrounds them. Hence, applying a Gestalt theoretic perspective on the user experience of context-aware mobile computer systems captures, in essence, the cognitively perceived ensemble of technology and context, and provides a foundation for rules about how this relationship can be exploited in interaction design.

This research is still ongoing and evolving. Motivated by the promising outcomes from the initial analysis of our empirical data presented in this paper, we are reanalysing the original video recordings from our evaluations in more detail. Our further research will expand on the descriptions of Gestalt theory principles as experienced by people in relation to their use of

Can content in the user interface be grouped with objects in the

Can pieces of information in the user interface and in the surroundings be combined to create a meaningful larger whole?

user interface and its context?

Does the system leave out redundant information already apparent through

Does the system align information representations in the user interface with the user's surroundings?

Does the system allow the user to align information representations in the user interface with their surroundings?

Does the system support user experiences that evolve over longer periods of

Does the system let the users extrapolate on their own and others' previous experiences in a place?

Does the content of the system accumulate over time on the basis of peoples' use of it?

with corresponding objects in the physical surroundings?

Does the user interface match elements in the surroundings, such as prominent signage, landmarks, and visual style of a place or area? 
location-based services. Finally, we are elaborating on the preliminary questions stated in Table 1 towards developing a set of Gestalt-based design heuristics for the user experience of location-based services on mobile devices.

\section{ACKNOWLEDGMENTS}

This research is supported by the Danish Technical Research Council (26-04-0026). The authors thank everyone participating in the field studies. We also thank Steve Howard and Bharat Dave for valuable input on the project.

\section{REFERENCES}

[1] BBC (2002) Mobile users unexcited by 3G, BBC News, June 18, 2002, http://news.bbc.co.uk/1/hi/business/2050994.stm (accessed 6 May 07)

[2] Behrens, R. (1984) Design in the Visual Arts, Prentice-Hall, Englewood Cliffs, NJ.

[3] Benyon, D., Turner, P. and Turner, S. (2005) Designing Interactive Systems, Addison-Wesley, Harlow, England.

[4] Borchers, J., Deussen, O., Klingert, A. and Knorzer, C. (1996) Layout Rules for Graphical Web Documents, Computer Graphics, 20 (3), 415-426.

[5] Chang, D., Dooley, L. and Tuovinen, J. (2001) Gestalt Theory in Visual Screen Design - A New Look at an Old Subject, Proc. WCCE'01, Volume 8, Copenhagen, Denmark, 5-12.

[6] Chang, D. and Nesbitt, K. (2005) Developing Gestalt-based Design Guidelines for Multi-sensory Displays, Proc. MMUI2005, Workshop on Multi-modal User Interaction, Sydney, Australia, ACS.

[7] Costolo, D. (2002) Mobile Operators Seek Incremental Revenue from the Mobile Internet, Wireless Business \& Technology, 2 (2). SYS-con Media.

[8] Dix, A., Finlay, J., Abowd, G., Beale, R. (1998) HumanComputer Interaction, Prentice Hall Europe, London.

[9] Dourish, P. (2004) What do we talk about when we talk about context? Personal and Ubiquitous Computing, 2004(8):19-30.

[10] Driscoll, M. P. (1993) Psychology of Learning for Instruction, Allyn \& Bacon, Needham Heights, MA.

[11] Ericsson (2007) The 2006 Australian Survey. Ericsson Consumer and Enterprise Lab. 11 January 2007 http://www.ericsson.com/au/ericsson/press/2006/Consumer_ Lab_2007_public.pdf (accessed 6 May 07).

[12] Forrester (2006) Breaking The Mobile Internet's Low Adoption Spell - Best Practices That Will Boost The Mobile Internet's Appeal For Content Firms And Consumers, Forrester Research Report, December 5, 2006

[13] Fithian, R., Iachello, G., Moghazy, J., Pousman, Z. and Stasko J. (2003) The Design and Evaluation of a Mobile Location-Aware Handheld Event planner, Proc. Mobile HCI 2003, LNCS, Springer-Verlag, Berlin.

[14] Flieder, K. and Modritscher, F. (2006) Foundations of a Pattern Language Based on Gestalt Principles, Proc. CHI 2006, Work-in-Progress, Montreal, Quebec, Canada.
[15] Frøkjær E. and Hornbæk K. (2007) Metaphors of Human Thinking for Usability Inspection and Design. Transactions on Computer-Human Interactions, TOCHI (to appear).

[16] Frøkjær E. and Hornbæk K. (2002) Metaphors of Human Thinking in HCI: Habit, Stream of Thought, Awareness, Utterance, and Knowing. Proceedings of HF 2002, Nov. 2527, 2002, Melbourne, Australia.

[17] Hinckley, K., Pierce, J., Horvitz, E. and Sinclair, M. (2005) Foreground and Background Interaction with SensorEnhanced Mobile Devices. Transactions on ComputerHuman Interaction, 12(1): 31-52.

[18] Hsiao, S. and Chou, J. (2006) A Gestalt-like perceptual measure for home page design using fuzzy entropy approach, International Journal of Human-Computer Studies, 64, 137156.

[19] Johnson, P. (1998) Usability and Mobility; Interactions on the move, Proc. Mobile HCI 1998, Glasgow, Scotland, GIST Technical Report G98-1.

[20] Jones, Q., Grandhi, S.A., Terveen, L. and Whittaker, S. (2004) People-to-People-to-Geographical-Places: The P3 Framework for Location-Based Community Systems. Computer Supported Cooperative Work, 2004(13): 249-282.

[21] Kaasinen, E. (2003) User Needs for Location-Aware Mobile Services, Personal and Ubiquitous Computing, 7, 70-79.

[22] Kjeldskov, J. and Paay, J. (2006) Public Pervasive Computing: making the Invisible Visible. IEEE Computer, 39(9):60-65.

[23] Lauesen, S. (2005) User Interface Design: A software engineering perspective, Addison-Wesley, Harlow, England.

[24] Lee, I., Kim, J. and Kim, J. (2005) Use Contexts for the Mobile Internet: A Longitudinal Study Monitoring Actual Use of Mobile Internet Services, IJHCI, 18(3), 269-292.

[25] Moore, P. and Fitz, C. (1993) Gestalt Theory and Instructional Design, Journal of Technical Writing and Communication, 23 (2), 137-157.

[26] Mullet, K. and Sano, D. (1995) Designing Visual Interfaces: Communication oriented techniques, Prentice Hall, Englewood Cliffs, NJ.

[27] Oviatt, S., Coulston, R., Tomko, S., Xiao, B., Lunsford, R., Wesson, M. and Carmichael, L. (2003) Toward a Theory of Organized Multimodal Integration Patterns during HumanComputer Interaction, Proc. ICMI'03, Vancouver, British Columbia, Canada, ACM, 44-51.

[28] Paay, J. and Kjeldskov, J. (2006) Understanding Situated Social Interactions: A Case Study of Public Places in the City, Computer-Supported Cooperative Work (to appear).

[29] Preece, J., Rogers, Y., Sharp, H., Benyon, D., Holland, S. and Carey, T. (1994) Human-Computer Interaction, Addison-Wesley, Wokingham, England.

[30] Roth, S. (1995) Visual Literacy and the Design of Digital Media, Computer Graphics, November 1995, 45-47.

[31] Sacher, H. and Loudon, G. (2002) Uncovering the New Wireless Interaction Paradigm, Interactions, 9(1), 17-23.

[32] Smith-Gratto, K. and Fisher, M. (1998-99) Gestalt Theory: A Foundation for Instructional Screen Design, Journal of Educational Technology Systems, 27 (4), 361-371. 